\title{
Schizophrenia genetics: uncovering positional candidate genes
}

\author{
Maria Karayiorgou ${ }^{*, 1}$ and Joseph A Gogos ${ }^{2}$ \\ ${ }^{1}$ The Rockefeller University, Laboratory of Human Neurogenetics, New York, NY, USA; ${ }^{2}$ Columbia University Medical \\ Center, Department of Physiology \& Cellular Biophysics, Center for Neurobiology \& Behavior, New York, NY, USA
}

The efforts to decipher the genetic causes of schizophrenia, one of the most devastating mental illnesses, have reached a turning point. Several linkage findings in schizophrenia have been replicated and, in the last few years, have been followed by systematic fine-mapping efforts to identify positional susceptibility genes. Here, we outline the evidence supporting each of the proposed positional candidate genes and identify some general areas of caution in their interpretation. Several of these findings hold considerable promise both for understanding the neuropathology of this brain disorder, the causes of which remain a mystery, but also for development of novel, mechanism-based treatments for the patients.

European Journal of Human Genetics (2006) 14, 512-519. doi:10.1038/sj.ejhg.5201587; published online 22 February 2006

Keywords: schizophrenia; gene; linkage; association

\section{Introduction}

Schizophrenia is a devastating psychiatric disorder characterized mainly by 'positive symptoms' that include delusions and hallucinations, 'negative symptoms' that include blunted emotions and social isolation, and cognitive deficits that include impairments in executive function, attention and working memory. ${ }^{1}$ The disease onsets usually in late adolescence or early adulthood and follows an episodic and deteriorative course where the prognosis becomes worse with each episode. ${ }^{2,3}$ It is estimated that $1 \%$ of the population may suffer from schizophrenia worldwide, but the disorder is more prevalent in families where schizophrenia has previously been diagnosed. ${ }^{4}$ Similar to many common, complex disorders, schizophrenia is a multifactorial disorder characterized, to a large extent, by the contribution of multiple susceptibility genes, which may interact, in a stochastic manner, with epigenetic processes and environmental

*Correspondence: Professor M Karayiorgou, The Rockefeller University, Laboratory of Human Neurogenetics, 1230 York Avenue, Box \#313, New York, NY 10021, USA. Tel: 212327 7328; Fax: 212327 7329;

E-mail: karayim@rockefeller.edu

Received 4 July 2005; revised 14 December 2005; accepted 21 December 2005; published online 22 February 2006 factors. ${ }^{5}$ Furthermore, it is likely that the disease presents etiologic heterogeneity, in the sense that different combinations of these factors could lead to very similar phenotypic outcomes.

Gene identification is an important milestone for understanding the disease pathophysiology. However, it has proven to be an extraordinarily difficult task because no single gene is necessary or sufficient to cause the disease but instead, many susceptibility genes with small effects act in combinations to increase the risk of illness. In the past 3 years, significant advances in gene discovery have taken place fueled by the completion of the sequencing of the human genome, the readily available technology for high-throughput genomic analysis, and the generation of new analytical and bioinformatics tools. Several susceptibility genes have been proposed, each supported by varying degrees of evidence. Gene discovery ensued after approximately 20 genomewide scans took place. In this recently emerged context, a critical reviewer of the literature should be concerned with issues regarding the extent of coverage of the implicated loci, consistency of the risk allele or risk haplotype across studies, the structure of the samples used in the original and replication studies, publication bias against negative reports, phenotypic heterogeneity and supporting biological data. As it is 
becoming increasingly clear that unreliable results may be obtained when allele frequencies differ notably among subpopulations not represented equally between cases and controls, ${ }^{6}$ the possibility that original or replication studies using case-control samples are false positives (or negatives) is a major source of concern. This issue is relevant to all common, complex disorders, but it is likely to be more pronounced in genetic studies of psychiatric disorders, which are confounded by a larger degree of phenotypic heterogeneity. In addition, several of the original or 'replication' samples have been used repeatedly in genetic association studies making the issue of multiple testing corrections highly relevant. These are not merely theoretical considerations as they can lead to striking inconsistencies among variant alleles and haplotypes implicated in various replication studies. Publication bias almost certainly affects the level of confidence ascribed to any given susceptibility gene. For example, negative studies are less likely to be submitted for publication and when they are submitted they are less likely to be published in the same journals where the original discovery was reported. As an end result, negative studies are more likely to accumulate with considerable delay or not at all. As alluded to above, phenotypic heterogeneity can also contribute to the uncertainties and inconsistencies associated with genetic research in schizophrenia. Phenotypic heterogeneity is to be expected due to the complexity of the affected organ (the brain), but the majority of genetic studies by relying on a categorical binary diagnosis ('affected' $v s$ 'unaffected') do not take into account the possible differences in representation among different samples of the various components of the illness. Therefore, claims that 'gene $\mathrm{X}$ has been replicated in eight out of 10 studies' should be taken with a grain of salt and a more careful analysis of the properties of the employed samples and the methods used is necessary to determine the validity of such claims.

The recent gene discovery studies promise to provide researchers with important clues regarding the genetic causes of schizophrenia. In the absence of a 'smoking gun' for most candidate genes, that is a well-defined and fully penetrant mutation of the kind found in Mendelian disorders, it is important to balance human genetic and hard biological evidence against the need for timely identification of targets and improvements in therapy. Biological data can be obtained by genetic studies of endophenotypes, provided they are designed to avoid all the pitfalls described above (such as population stratification), which are associated with genetic studies of the clinical syndrome. Most importantly, in our opinion, biological insights can be provided by generation of reliable animal models. Identification of susceptibility genes will permit the design of much more incisive studies to illuminate the physiological and biochemical etiology of the disease by examining the gene products in the context of a model organism and their impact on the development of the disorder.

\section{Candidate genes through positional cloning}

In this review, we discuss the genetic data for recently emerged strong positional candidate genes that were identified through systematic follow-up of linkage signals (in chronological order of appearance of the reports), their possible function(s), as well as biological data accumulating from relevant animal models, when applicable. With one exception for the gene for catechol-O-methyltransferase (COMT), space constraints do not allow us to discuss available genetic data for a set of candidate genes (such as PPP3CC or RGS4), located in the general vicinity of linkage signals and identified through convergent genetic and biological evidence, rather than systematic positional cloning approaches. Indeed, the location of these genes begs the question whether the recurrent observation of clustering of candidate susceptibility genes may indicate that more than one gene may contribute to at least some of the linkage signals observed in psychiatric disorders. Finally, due to space limitations, other genes that could be good candidates (such as DRD3, CHRNA2, BDNF, GAD2, $A K T 1$ ), but do not strictly conform to the criteria outlined above, are also not discussed here.

In 2002, four strong candidate schizophrenia susceptibility genes were identified through systematic positional cloning efforts ${ }^{7}$ in regions of linkage. The genes were: PRODH (proline dehydrogenase, chromosome 22q11), DTNBP1 (dystrobrevin-binding protein 1, or dysbindin, chromosome 6p), NRG1 (neuregulin 1, chromosome 8p) and $G 72$ (chromosome 13q).$^{8-11}$ More recently, additional candidate genes have been identified by linkage disequilibrium (LD) mapping methods using single nucleotide polymorphisms (SNPs) in previously identified linkage peaks.

\section{Proline dehydrogenase}

PRODH encodes an enzyme that metabolizes L-proline, a putative neuromodulatory amino acid that may directly influence glutamatergic transmission, ${ }^{12}$ which is believed to play a central role in the pathophysiology of schizophrenia. The gene maps to chromosome 22q11. An unequivocal association between hemizygous deletions of the 22q11 locus and schizophrenia has been established. In light of positive linkage findings at the same locus, individual genes from this locus have been examined in systematic fine-mapping efforts. ${ }^{13}$ LD analysis using 72 SNPs in family samples identified an overtransmission of a haplotypic variant located at the $3^{\prime}$ end of the PRODH gene. ${ }^{8,14}$ This finding was recently replicated in two independent family samples, including a very large collection of 528 families from China ${ }^{15}$ and 274 families of Ashkenazi Jewish origin, ${ }^{16}$ although one negative family 
study has also been reported. ${ }^{17}$ Moreover, $3^{\prime}$ end variants of the gene were also identified as a risk factor for development of psychotic symptoms during adolescence in children with $22 \mathrm{q} 11$ microdeletions. ${ }^{18}$ The functional consequences of the implicated haplotypic variants, which are consistently located at the $3^{\prime}$ end of the gene, are still unknown. However, the Liu et $a l^{8}$ study identified additional rare variants of the $P R O D H$ gene, which affect highly conserved amino acids. These variants are present either exclusively or in higher frequencies in schizophrenic patients and are generated through gene conversion from a nearby pseudogene. ${ }^{8}$ Several of these variants lead to drastic reductions in enzymatic activity. ${ }^{19}$ The same variants were described in schizophrenic patients in an independent study, which also identified a small deletion encompassing the $P R O D H$ gene in a schizophrenic patient. $^{20}$ In addition to being one of the most variable genes in the human genome, the $P R O D H$ gene is haploinsufficient: heterozygous deletions of $P R O D H$ and the presence of heterozygous mutations of the $P R O D H$ gene are associated with moderate hyperprolinemia $(300-600 \mathrm{mmol} / \mathrm{l}) .^{20,21}$ As a result of the hemizygous nature of the $22 \mathrm{q} 11$ microdeletions, haploinsufficiency (gene dosage-dependence) is likely to be an important property of any gene that modulates the emergence of the $22 \mathrm{q} 11$ psychiatric phenotypes, as it was the case for $T b x 1$, a gene that modulates in a dosage-dependent manner the cardiac features associated with these microdeletions. ${ }^{22} \mathrm{~A}$ mutation in the mouse ortholog of the human $P R O D H$ gene in the Pro/Re hyperprolinemic mouse strain has been described. $^{23}$ These mice demonstrate an increased neurotransmitter release and abnormal plasticity at glutamatergic synapses, as well as distinct abnormalities in dopamine turnover and signaling in the frontal cortex. ${ }^{24}$ Cortical dopaminergic dyseregulation is accompanied by local increase in transcript and protein levels of the Comt gene (also located within the 22q11 microdeletion locus, see below) that is likely to represent a homeostatic response. Thus, these animal model studies strongly suggest that, within the context of the 22q11-associated schizophrenia, PRODH deficiency likely acts as a primary deficit whose effects are buffered by COMT activity and provide a framework for understanding the genetic architecture of the schizophrenia risk.

\section{Dystrobrevin-binding protein 1, or dysbindin}

Fine-mapping efforts undertaken as a follow-up to evidence for linkage on chromosome $6 \mathrm{p} 24-22$ in a sample of Irish families, led to identification of an association with schizophrenia of genetic variants in the DTNBP1 gene (dysbindin). ${ }^{9}$ Most replication samples used $(N=9)$ were case-control samples. ${ }^{25-29}$ Replication of this association has also been attempted in seven family samples, with replications observed in five of them. ${ }^{16,30-33}$ In the positive studies there are inconsistencies among the implicated alleles or haplotypes. If these inconsistencies are not a product of population stratification or multiple testing, they could be explained by the presence of distinct variations affecting different functional elements within the gene that have emerged independently on a more recent ancestral background. Alternatively, the signal may be due to variants in a neighboring gene or genes in LD with DTNBP1 variants. Recently, functional significance has been ascribed to some of the implicated alleles or haplotypes. $^{34}$ DTNBP1 is a member of the biogenesis of lysosome-related organelles complex (BLOC), as well as the dystrophin protein complex (DPC). ${ }^{35,36}$ The protein is ubiquitously expressed in the brain. Two recent studies showed a decrease of DTNBP1 mRNA in dorsolateral prefrontal cortex (DLPFC) and hippocampus of schizophrenic patients when compared to controls. ${ }^{37,38}$ Preliminary in vitro evidence suggests that knockdown of endogenous dysbindin protein results in the reduction of presynaptic protein expression and glutamate release, suggesting that dysbindin might influence exocytotic glutamate release. ${ }^{27}$

\section{Neuregulin 1}

A broad region on chromosome 8p12-21 has been consistently implicated in schizophrenia by multiple linkage studies, including a study of 33 extended Icelandic families. Fine-mapping across the genomic region of maximal linkage in this set of families detected an association between schizophrenia and several haplotypes at the NRG1 locus. A core haplotype at the $5^{\prime}$ end of the gene comprising several markers within a 290-kb block of LD showed highly significant association with schizophrenia. ${ }^{10}$ While several replication studies have taken place it is still unclear which variants or haplotypes are involved. Eight of the replication samples used were case-control samples. ${ }^{39-46}$ In addition, 8 family samples were also used for replication. In these, less than half show some evidence for association, but with haplotypes other than the one originally described. ${ }^{16,33,44-49}$ Of concern are some dramatic differences in the frequency of haplotypes reported between different samples, ${ }^{45,46}$ where the frequencies range from 1 to $10 \%$. This could indicate either substantial heterogeneity in the LD structure across the NRG1 locus or the presence of multiple risk alleles. In the absence of any functional significance for any of the implicated haplotypes it is difficult to interpret further the genetic data that is published at the time of this writing. The NRG1 gene is an attractive candidate as it it encodes a well-characterized protein involved in a wide variety of neuronal, complex functions, ranging from neuronal survival to myelination and synaptic plasticity. ${ }^{50}$ Several general and conditional Nrg1 knockout mice have been described, ${ }^{51,52}$ but it is not clear if they can be used reliably to model the gene's contribution to schizophrenia since the nature of the 
pathogenic contribution of this gene to schizophrenia is currently unknown.

\section{G72}

Another strong linkage signal for both schizophrenia and bipolar disorder has been identified on chromosome 13q32-34. This linkage signal is one of the most consistent ones in the literature ${ }^{53,54}$ and has prompted fine-mapping efforts. Significant association with schizophrenia was described for several SNPs and haplotypes at the G72 locus in a French-Canadian case-control sample, with the association for two SNPs being replicated in a Russian case-control cohort. ${ }^{11}$ Interestingly, an association between variants at the $G 72$ locus and bipolar disorder has also been described. ${ }^{55}$ G72 association with schizophrenia has been observed in several additional samples (some case-control $^{56-58}$ and some family-based samples ${ }^{59,60}$ ) with evidence for allelic heterogeneity. Negative studies have also been reported. ${ }^{61}$ Enzymatic studies suggested a potential interaction with D-amino-acid oxidase (DAAO) that modulates its enzymatic activity and thus could indirectly affect glutamatergic signaling. ${ }^{11,62}$ The notion that G72 acts via modulation of DAAO activity has acquired momentum in the field, but there is no direct in vivo demonstration of such effect.

\section{Disrupted in schizophrenia 1}

Disrupted in schizophrenia 1 (DISC1) is one of two genes isolated from a chromosome 1q42 translocation breakpoint previously described to segregate with psychopathology in a large Scottish family. The other gene is DISC2 and is a noncoding, presumably regulatory RNA. ${ }^{63}$ Alternative hypotheses about involvement of the reciprocal translocation breakpoint on chromosome 11 have been proposed. ${ }^{64}$ Although DISC1 was originally described 5 years ago, interest in it was renewed only recently when large-scale linkage ${ }^{65,66}$ and follow-up systematic association studies in families from Finland identified DISC1 as a positional candidate from the 1q42 locus. ${ }^{67}$ DISC1 association with schizophrenia has been observed in some additional samples with evidence for allelic heterogeneity, although negative studies have also been reported. ${ }^{16,67,68}$ Interestingly, a family afflicted with schizophrenia and schizoaffective disorder was recently shown to segregate a rare frameshift variant of the gene. ${ }^{69}$ In one recent preliminary imaging study variation in the DISC1 gene was associated with altered hippocampal structure and function in healthy subjects, ${ }^{70}$ whereas an independent study implicated DISC1 variation in visual working memory performance. ${ }^{71}$ DISC1 is a complex gene with poorly understood involvement in development and plasticity. It is associated with numerous cytoskeletal proteins, and it may be involved in a variety of cellular functions, including centrosomal and microtubule function, cell migration, neurite outgrowth, membrane trafficking of receptors, mitochondrial function and phosphodiesterase signaling. ${ }^{72}$

\section{Carboxyl-terminal PDZ ligand of neuronal nitric oxide synthase}

Brzustowicz et $a l^{73}$ have previously reported evidence for linkage at 1q22. Using 14 microsatellite markers and 15 SNPs from a subregion of the linkage locus ${ }^{74}$ produced nominally significant evidence of LD between schizophrenia and a subset of markers located within the genomic region of carboxyl-terminal PDZ ligand of neuronal nitric oxide synthase $(C A P O N)$, making it a prime positional candidate from the schizophrenia susceptibility locus on 1q22. An abnormal expression pattern of this gene was observed in brains from individuals with schizophrenia or bipolar disorder. ${ }^{75}$ Two case-control replication studies (one positive and one negative) have been reported. ${ }^{76,77}$ CAPON is involved in NMDA receptorcoupled nitric oxide signaling. ${ }^{78}$

\section{ZDHHC8}

This gene was identified in the same LD screen of the 22q11 locus that identified the association between the PRODH gene and schizophrenia. ${ }^{8,14}$ Five SNPs from an 80-kb LD block were significantly associated with schizophrenia. The most significantly associated SNP, rs175174, maps in intron 4 of the ZDHHC8 gene and was shown to affect the ratio of an intron 4-containing unspliced form (that encodes a putative truncated form of the protein) over the fully spliced form by $\sim 25-30 \% .{ }^{79}$ This small change in the levels of the active protein was associated with $\sim 1.5$-fold increase in the disease risk in two tested family samples of patients not carrying the 22q11 deletion. ${ }^{14,79}$ It is, of course, possible that other variants of the gene (affecting distinct aspects of its complex splicing or its expression level) might modulate the disease risk in other patient samples. One positive and one negative familybased study have been reported so far. ${ }^{80,81}$ Although the general involvement of this gene in schizophrenia awaits analysis of additional family samples, the effect of the gene is predicted to be much stronger in individuals with $22 \mathrm{q} 11$ deletions and schizophrenia, where a 50\% (or 65\% when the nondeleted allele carries the risk SNP rs175174 variant) decrease in ZDHHC8 activity levels is predicted. ZDHHC8 is predicted to encode a transmembrane palmitoyltransferase that modifies PSD-95 among other targets (Mukai J, Dhilla A, MK, and JAG, unpublished) and could play an important role in excitatory synaptic transmission. ${ }^{82}$

\section{Trace amine receptor 4}

A broad area on chromosome $6 \mathrm{q}(6 \mathrm{q} 13-\mathrm{q} 26)$ has also been implicated in schizophrenia in linkage studies using European-ancestry and African American schizophrenia pedigrees. ${ }^{83}$ Fine-mapping efforts focusing on band q23.2 using 31 SNPs and a follow-up higher density screen using 
23 SNPs over a 21.6-kb region identified trace amine receptor 4 (TAAR6) as a prime positional candidate ${ }^{84}$ for the schizophrenia susceptibility locus on $6 q 23.2$. Two negative replication studies have been reported. ${ }^{85,86}$ However, an independent study implicated the trace amine receptor genes at $6 \mathrm{q} 23.2$ in susceptibility to bipolar disorder. ${ }^{87}$ TAAR6 is a GPCR widely expressed in the brain. ${ }^{88}$

\section{Epsin 4}

Chromosome $5 q 33$ is a region that has previously shown strong evidence of linkage to schizophrenia, with four LOD scores $>3.0$ in independent linkage studies. Four adjacent markers (and associated haplotypes) at the $5^{\prime}$ end of the Epsin 4 gene, which is located in this region, showed significant evidence of LD with schizophrenia in a finemapping study that employed 450 unrelated English, Irish, Welsh, and Scottish research subjects with schizophrenia and 450 ancestrally matched supernormal controls. ${ }^{89}$ The Epsin 4 gene encodes the clathrin-associated protein enthoprotin, which has a role in transport and stability of neurotransmitter vesicles at the synapses and within neurons. No replication studies have been reported yet.

\section{Gamma-aminobutyric acid receptor subunit gene cluster}

Chromosome 5q31-q35 was implicated in Portuguese schizophrenia families ${ }^{90}$ and was supported by subsequent meta-analysis. A group of gamma-aminobutyric acid (GABA)A receptor subunit genes (GABRA1, GABRA6, $G A B R B 2, G A B R G 2$ and $G A B R P)$ that map within this linkage peak were investigated in Portuguese patients and associations with SNPs and haplotypes in GABRA1, GABRP and GABRA6 were detected. ${ }^{91}$ The GABRA1 and $G A B R P$ findings were replicated in an independent German family-based sample. ${ }^{91}$ These genes are plausible candidates based on prior evidence for GABA system involvement in schizophrenia. ${ }^{92}$

\section{Catechol-O-methyltransferase}

The gene is located in the $22 \mathrm{q} 11$ region between the PRODH and ZDHHC8 genes (see previous section on positional candidate genes). COMT is also an attractive functional candidate gene since it is involved in the breakdown of dopamine. Several studies testing directly for association between variants from this gene and schizophrenia have taken place. One variant in particular, in codon 158 that affects enzymatic activity depending on the presence of Val (high activity) or Met (low activity), has been studied extensively. It has been proposed that the high activity Val allele increases the risk for schizophrenia, but the genetic association results are equivocal. ${ }^{93-99}$ The same allele was shown in some studies to impair executive function, which is affected in schizophrenic patients. ${ }^{100,101}$ More recent studies in animal models, however, suggested that low activity of this enzyme could be a risk factor for schizophrenia by failing to buffer the effect of other primary mutations that affect dopamine turnover and signaling in the cortex. ${ }^{24}$ This prediction was supported by the results of a longitudinal follow-up study of children with 22q11 microdeletions, which revealed that the lowactivity form of the enzyme (Met158) is a risk factor for decline in prefrontal cortical volume and cognition, as well as for the consequent development of psychotic symptoms during adolescence, in these children. ${ }^{18}$ Overall, a potential contribution of COMT to schizophrenia in general, is likely to be complex.

\section{Future directions}

Two recent meta-analyses ${ }^{102,103}$ implicated (under moderate stringency) approximately 12 regions of the genome as likely to contain schizophrenia susceptibility genes $(2 \mathrm{p}, 5 \mathrm{q}$, $3 p, 11 q, 2 q, 1 q, 22 q, 8 p, 6 p, 20 p, 13 q$ and 14q). This is most likely to be an underestimate. Nevertheless, even if we take the meta-analytic studies at face value, and assume that the already isolated positional candidates can solely account for the local linkage signals (a property that has not been demonstrated for any of them) there are still several 'orphan' linkage loci that await the identification of positional candidate genes. This task will be facilitated by the sequencing of the human genome and the identification of SNPs and their LD patterns over virtually all segments of the human genome. ${ }^{104}$ It is the ultimate hope that the identification and in vivo characterization of schizophrenia susceptibility genes will lead to the discovery of novel, improved mechanism-based therapies that target susceptibility genes or affected molecular pathways.

\section{References}

1 American Psychiatric Association: Diagnostic and Statistical Manual, 4th edn, American Psychiatric Association: Washington, DC, (1994).

2 Lieberman JA, Perkins D, Belger A et al: The early stages of schizophrenia: speculations on pathogenesis, pathophysiology, and therapeutic approaches. Biol Psychiatry 2001; 50: 884-897.

3 Perkins DO, Gu H, Boteva K, Lieberman JA: Relationship between duration of untreated psychosis and outcome in firstepisode schizophrenia: a critical review and meta-analysis. Am J Psychiatry 2005; 162: 1785-1804.

4 Gottesman II, Shields J: Schizophrenia: The Epigenetic Puzzle. Cambridge University Press: Cambridge, UK, 1982.

5 Karayiorgou M, Gogos JA: A turning point in schizophrenia genetics. Neuron 1997; 19: 967-979.

6 Campbell CD, Ogburn EL, Lunetta KL et al: Demonstrating stratification in a European American population. Nat Genet 2005; 37: 868-872.

7 Riley JH, Allan CJ, Lai E, Roses A: The use of single nucleotide polymorphisms in the isolation of common disease genes. Pharmacogenomics 2000; 1: 39-47.

8 Liu H, Heath SC, Sobin C et al: Genetic variation at the 22q11 PRODH2/DGCR6 locus presents an unusual pattern and increases susceptibility to schizophrenia. Proc Natl Acad Sci USA 2002; 99: 3717-3722. 
9 Straub RE, Jiang Y, MacLean CJ et al: Genetic variation in the 6 22.3 gene DTNBP1, the human ortholog of the mouse dysbindin gene, is associated with schizophrenia. Am J Hum Genet 2002; 71: 337-348.

10 Stefansson H, Sigurdsson E, Steinthorsdottir V et al: Neuregulin 1 and susceptibility to schizophrenia. Am J Hum Genet 2002; 71: $877-892$.

11 Chumakov I, Blumenfeld M, Guerassimenko O et al: Genetic and physiological data implicating the new human gene G72 and the gene for D-amino acid oxidase in schizophrenia. Proc Natl Acad Sci USA 2002; 99: 13675-13680.

12 Renick SE, Kleven DT, Chan J et al: The mammalian brain highaffinity L-proline transporter is enriched preferentially in synaptic vesicles in a subpopulation of excitatory nerve terminals in rat forebrain. J Neurosci 1999; 19: 21-33.

13 Karayiorgou M, Gogos JA: The molecular genetics of the 22q11associated schizophrenia. Mol Brain Res 2004; 132: 95-104.

14 Liu H, Abecasis GR, Heath SC et al: Genetic variation in the 22q11 locus and susceptibility to schizophrenia. Proc Natl Acad Sci USA 2002; 99: 16859-16864.

$15 \mathrm{Li} \mathrm{T}, \mathrm{Ma} \mathrm{X}$, Sham PC et al: Evidence for association between novel polymorphisms in the PRODH gene and schizophrenia in a Chinese population. Am J Med Genet 2004; 129B: 13-15.

16 Fallin MD, Lasseter VK, Avramopoulos D et al: Bipolar I disorder and schizophrenia: a 440-single-nucleotide polymorphism screen of 64 candidate genes among ashkenazi jewish caseparent trios. Am J Hum Genet 2005; 77: 918-936.

17 Williams HJ, Williams N, Spurlock G et al: Association between PRODH and schizophrenia is not confirmed? Mol Psychiatry 2003; 8: 644-645.

18 Gothelf D, Eliez S, Thompson T et al: COMT genotype predicts longitudinal cognitive decline and psychosis in 22q11.2 deletion syndrome. Nat Neurosci 2005; 8: 1500-1502.

19 Bender HU, Almashanu S, Steel G et al: Functional consequences of PRODH missense mutations. Am J Hum Genet 2005; 76: $409-420$.

20 Jacquet H, Raux G, Thibaut $\mathrm{F}$ et al: PRODH mutations and hyperprolinaemia in a subset of schizophrenic patients. Hum Mol Genet 2002; 11: 2243-2249.

21 Jacquet H, Berthelot J, Bonnemains C et al: The severe form of type I hyperprolinaemia results from homozygous inactivation of the PRODH gene. J Med Genet 2003; 40: e7 [PMID: 12525555].

22 Merscher S, Funke B, Epstein JA et al: TBX1 is responsible for cardiovascular defects in velo-cardio-facial/DiGeorge syndrome. Cell 2001; 104: 619-629.

23 Gogos JA, Santha M, Takacs Z et al: The gene encoding proline dehydrogenase modulates sensorimotor gating in mice. Nat Genet 1999; 21: 434-439.

24 Paterlini M, Zakharenko SS, Lai WS et al: Transcriptional and behavioral interaction between 22q11.2 orthologs modulates schizophrenia-related phenotypes in mice. Nat Neurosci 2005; 8: $1586-1594$

25 Van Den Bogaert A, Schumacher J, Schulze TG et al: The DTNBP1 (dysbindin) gene contributes to schizophrenia, depending on family history of the disease. Am J Hum Genet 2003; 73: $1438-1443$.

26 Funke B, Finn CT, Plocik AM et al: Association of the DTNBP1 locus with schizophrenia in a US population. Am J Hum Genet 2004; 75: 891-898.

27 Numakawa T, Yagasaki Y, Ishimoto T et al: Evidence of novel neuronal functions of dysbindin, a susceptibility gene for schizophrenia. Hum Mol Genet 2004; 13: 2699-2708.

28 Morris DW, McGhee KA, Schwaiger S et al: No evidence for association of the dysbindin gene (DTNBP1) with schizophrenia in an Irish population-based study. Schizophr Res 2003; 60: $167-172$.

29 Williams NM, Preece A, Morris DW et al: Identification in 2 independent samples of a novel schizophrenia risk haplotype of the dystrobrevin binding protein gene (DTNBP1). Arch Gen Psychiatry 2004; 61: 336-344.
30 Schwab SG, Knapp M, Mondabon S et al: Support for association of schizophrenia with genetic variation in the $6 \mathrm{p} 22.3$ gene, dysbindin, in sib-pair families with linkage and in an additional sample of triad families. Am J Hum Genet 2003; 72: 185-190.

31 Tang JX, Zhou J, Fan JB et al: Family-based association study of DTNBP1 in 6p22.3 and schizophrenia. Mol Psychiatry 2003; 8: $717-718$.

32 Kirov G, Ivanov D, Williams NM et al: Strong evidence for association between the dystrobrevin binding protein 1 gene (DTNBP1) and schizophrenia in 488 parent-offspring trios from Bulgaria. Biol Psychiatry 2004; 55: 971-975.

33 Hall D, Gogos JA, Karayiorgou M: The contribution of three strong candidate schizophrenia susceptibility genes in demographically distinct populations. Genes Brain Behav 2004; 3: 240-248.

34 De Luca V, Voineskos D, Shinkai T, Wong G, Kennedy JL: Untranslated region haplotype in dysbindin gene: analysis in schizophrenia. J Neural Transm 2005; 112: 1263-1267.

35 Benson MA, Newey SE, Martin-Rendon E, Hawkes R, Blake DJ: Dysbindin, a novel coiled-coil-containing protein that interacts with the dystrobrevins in muscle and brain. I Biol Chem 2001; 276: 24232-24241

36 Li W, Zhang $\mathrm{Q}$, Oiso N et al: Hermansky-Pudlak syndrome type 7 (HPS-7) results from mutant dysbindin, a member of the biogenesis of lysosome-related organelles complex 1 (BLOC-1). Nat Genet 2003; 35: 84-89.

37 Talbot K, Eidem WL, Tinsley CL et al: Dysbindin-1 is reduced in intrinsic, glutamatergic terminals of the hippocampal formation in schizophrenia. J Clin Invest 2004; 113: 1353-1363.

38 Weickert CS, Straub RE, McClintock BW et al: Human dysbindin (DTNBP1) gene expression in normal brain and in schizophrenic prefrontal cortex and midbrain. Arch Gen Psychiatry 2004; 61: 544-555.

39 Stefansson H, Sarginson J, Kong A et al: Association of neuregulin 1 with schizophrenia confirmed in a Scottish population. Am J Hum Genet 2003; 72: 83-87.

40 Williams NM, Preece A, Spurlock G et al: Support for genetic variation in neuregulin 1 and susceptibility to schizophrenia. Mol Psychiatry 2003; 8: 485-487.

41 Iwata N, Suzuki T, Ikeda $M$ et al: No association with the neuregulin 1 haplotype to Japanese schizophrenia. Mol Psychiatry 2004; 9: 126-127.

42 Corvin AP, Morris DW, McGhee $\mathrm{K}$ et al: Confirmation and refinement of an 'at-risk' haplotype for schizophrenia suggests the EST cluster, Hs.97362, as a potential susceptibility gene at the neuregulin-1 locus. Mol Psychiatry 2004; 9: $208-213$.

43 Tang JX, Chen WY, He G et al: Polymorphisms within $5^{\prime}$ end of the neuregulin 1 gene are genetically associated with schizophrenia in the Chinese population. Mol Psychiatry 2004; 9: $11-12$

44 Petryshen TL, Middleton FA, Kirby A et al: Support for involvement of neuregulin 1 in schizophrenia pathophysiology. Mol Psychiatry 2005; 10: 366-374.

$45 \mathrm{Li}$ T, Stefansson H, Gudfinnsson E et al: Identification of a novel neuregulin 1 at-risk haplotype in Han schizophrenia Chinese patients, but no association with the Icelandic/Scottish risk haplotype. Mol Psychiatry 2004; 9: 698-704.

46 Zhao X, Shi Y, Tang J et al: A case control and family based association study of the neuregulin 1 gene and schizophrenia. J Med Genet 2004; 41: 31-34.

47 Thiselton DL, Webb BT, Neale BM et al: No evidence for linkage or association of neuregulin-1 (NRG1) with disease in the Irish study of high-density schizophrenia families (ISHDSF). Mol Psychiatry 2004; 9: 777-783.

48 Yang JZ, Si TM, Ruan Y et al: Association study of neuregulin 1 gene with schizophrenia. Mol Psychiatry 2003; 8: 706-709.

49 Duan J, Martinez M, Sanders AR et al: Neuregulin 1 (NRG1) and schizophrenia: analysis of a US family sample and the evidence in the balance. Psychol Med 2005; 35: 1599-1610. 
50 Corfas G, Roy K, Buxbaum JD: Neuregulin 1-erbB signaling and the molecular/cellular basis of schizophrenia. Nat Neurosci 2004; 7: $575-580$.

51 Rimer M, Barrett DW, Maldonado MA, Vock VM, Gonzalez-Lima F: Neuregulin-1 immunoglobulin-like domain mutant mice: clozapine sensitivity and impaired latent inhibition. Neuroreport 2005; 16: 271-275.

52 Yang X, Kuo Y, Devay P, Yu C, Role L: A cysteine-rich isoform of neuregulin controls the level of expression of neuronal nicotinic receptor channels during synaptogenesis. Neuron 1998; 20: $255-$ 270. Erratum in Neuron 1998;20:823.

53 Blouin JL, Dombroski BA, Nath SK et al: Schizophrenia susceptibility loci on chromosomes $13 \mathrm{q} 32$ and $8 \mathrm{p} 21$. Nat Genet 1998; 20: 70-73.

54 Detera-Wadleigh SD, Badner JA, Berrettini WH et al: A highdensity genome scan detects evidence for a bipolardisorder susceptibility locus on $13 \mathrm{q} 32$ and other potential loci on 1q32 and 18p11.2. Proc Natl Acad Sci USA 1999; 96: 5604-5609.

55 Hattori E, Liu C, Badner JA et al: Polymorphisms at the G72/G30 gene locus, on 13q33, are associated with bipolar disorder in two independent pedigree series. Am J Hum Genet 2003; 72: $1131-1140$.

56 Wang $\mathrm{X}, \mathrm{He} \mathrm{G}, \mathrm{Gu} \mathrm{N}$ et al: Association of G72/G30 with schizophrenia in the Chinese population. Biochem Biophys Res Commun 2004; 319: 1281-1286.

57 Schumacher J, Jamra RA, Freudenberg $\mathrm{J}$ et al: Examination of G72 and D-amino-acid oxidase as genetic risk factors for schizophrenia and bipolar affective disorder. Mol Psychiatry 2004; 9: 203-207.

58 Korostishevsky M, Kaganovich M, Cholostoy A et al: Is the G72/ G30 locus associated with schizophrenia? single nucleotide polymorphisms, haplotypes, and gene expression analysis. Biol Psychiatry 2004; 56: 169-176.

59 Addington AM, Gornick M, Sporn AL et al: Polymorphisms in the 13q33.2 gene G72/G30 are associated with childhood-onset schizophrenia and psychosis not otherwise specified. Biol Psychiatry 2004; 55: 976-980.

60 Zou F, Li C, Duan S et al: A family-based study of the association between the G72/G30 genes and schizophrenia in the Chinese population. Schizophr Res 2005; 73: 257-261.

61 Mulle JG, Chowdari KV, Nimgaonkar V, Chakravarti A: No evidence for association to the G72/G30 locus in an independent sample of schizophrenia families. Mol Psychiatry 2005; 10: 431-433.

62 Mothet JP, Parent AT, Wolosker $\mathrm{H}$ et al: -serine is an endogenous ligand for the glycine site of the $N$-methyl-D-aspartate receptor. Proc Natl Acad Sci USA 2000; 97: 4926-4931.

63 Millar JK, Wilson-Annan JC, Anderson S et al: Disruption of two novel genes by a translocation co-segregating with schizophrenia. Hum Mol Genet 2000; 9: 1415-1423.

64 Klar AJS: A genetic mechanism implicates chromosome 11 in schizophrenia and bipolar diseases. Genetics 2004; 167: $1833-1840$.

65 Ekelund J, Hovatta I, Parker A et al: Chromosome 1 loci in Finnish schizophrenia families. Hum Mol Genet 2001; 10: $1611-1617$.

66 Ekelund J, Hennah W, Hiekkalinna T et al: Replication of 1q42 linkage in Finnish schizophrenia pedigrees. Mol Psychiatry 2004; 9: 1037-1041.

67 Hennah W, Varilo T, Kestilä $\mathrm{M}$ et al: Haplotype transmission analysis provides evidence of association for DISC1 to schizophrenia and suggests sex-dependent effects. Hum Mol Genet 2003; 12: 3151-3159.

68 Hodgkinson CA, Goldman D, Jaeger J et al: Disrupted in schizophrenia 1 (DISC1): association with schizophrenia, schizoaffective disorder and bipolar disorder. Am J Hum Genet 2004; 75: $862-872$

69 Sachs NA, Sawa A, Holmes SE, Ross CA, DeLisi LE, Margolis RL: A frameshift mutation in disrupted in schizophrenia 1 in an
American family with schizophrenia and schizoaffective disorder. Mol Psychiatry 2005; 10: 758-764.

70 Callicott JH, Straub RE, Pezawas L et al: Variation in DISC1 affects hippocampal structure and function and increases risk for schizophrenia. Proc Natl Acad Sci USA 2005; 102: 8627-8632.

71 Hennah W, Tuulio-Henriksson A, Paunio T et al: A haplotype within the DISC1 gene is associated with visual memory functions in families with a high density of schizophrenia. Mol Psychiatry 2005; 10: 1097-1103.

72 Sawa A, Snyder SH: Two genes link two distinct psychoses. Science 2005; 310: 1128-1129.

73 Brzustowicz LM, Hodgkinson KA, Chow EW, Honer WG, Bassett AS: Location of a major susceptibility locus for familial schizophrenia on chromosome 1q21-q22. Science 2000; 288: 678-682.

74 Brzustowicz LM, Simone J, Mohseni P et al: Linkage disequilibrium mapping of schizophrenia susceptibility to the CAPON region of chromosome 1q22. Am J Hum Genet 2004; 74: 1057-1063.

75 Xu B, Wratten N, Charych EI, Buyske S, Firestein BL, Brzustowicz LM: Increased expression in dorsolateral prefrontal cortex of CAPON in schizophrenia and bipolar disorder. PLoS Med 2005; 2: e263 [PMID: 16146415].

76 Zheng Y, Li H, Qin W et al: Association of the carboxyl-terminal PDZ ligand of neuronal nitric oxide synthase gene with schizophrenia in the Chinese Han population. Biochem Biophys Res Commun 2005; 328: 809-815.

77 Puri V, McQuillin A, Thirumalai S et al: Failure to confirm allelic association between markers at the CAPON gene locus and schizophrenia in a british sample. Biol Psychiatry 2006; 59: $195-197$.

78 Jaffrey SR, Snowman AM, Eliasson MJ, Cohen NA, Snyder SH: CAPON: a protein associated with neuronal nitric oxide synthase that regulates its interactions with PSD95. Neuron 1998; 20: $115-124$

79 Mukai J, Liu H, Burt RA et al: Evidence that the gene encoding ZDHHC8 contributes to the risk of schizophrenia. Nat Genet 2004; 36: 725-731.

80 Chen WY, Shi YY, Zheng YL et al: Case-control study and transmission disequilibrium test provide consistent evidence for association between schizophrenia and genetic variation in the 22q11 gene ZDHHC8. Hum Mol Genet 2004; 13: 2991-2995.

81 Glaser B, Schumacher J, Williams HJ et al: No association between the putative functional ZDHHC8 single nucleotide polymorphism rs175174 and schizophrenia in large European samples. Biol Psychiatry 2005; 58: 78-80.

82 el-Husseini Ael-D, Bredt DS: Protein palmitoylation: a regulator of neuronal development and function. Nat Rev Neurosci 2002; 3: 791-802.

83 Levinson DF, Holmans P, Straub RE et al: Multicenter linkage study of schizophrenia candidate regions on chromosomes $5 \mathrm{q}$, 6q, 10p, and 13q: schizophrenia linkage collaborative group III. Am J Hum Genet 2000; 67: 652-663.

84 Duan J, Martinez M, Sanders AR et al: Polymorphisms in the trace amine receptor 4 (TRAR4) gene on chromosome 6q23.2 are associated with susceptibility to schizophrenia. Am J Hum Genet 2004; 75: 624-638.

85 Duan S, Du J, Xu Y et al: Failure to find association between TRAR4 and schizophrenia in the Chinese Han population. J Neural Transm 2006; 113: 381-385.

86 Ikeda M, Iwata N, Suzuki T et al: No association of haplotypetagging SNPs in TRAR4 with schizophrenia in Japanese patients. Schizophr Res 2005; 78: 127-130.

87 Abou Jamra R, Sircar I, Becker T et al: A family-based and casecontrol association study of trace amine receptor genes on chromosome 6q23 in bipolar affective disorder. Mol Psychiatry 2005; 10: 618-620.

88 Borowsky B, Adham N, Jones KA et al: Trace amines: identification of a family of mammalian $\mathrm{G}$ protein-coupled receptors. Proc Natl Acad Sci USA 2001; 98: 8966-8971. 
89 Pimm J, McQuillin A, Thirumalai S et al: The Epsin 4 gene on chromosome $5 q$, which encodes the clathrin-associated protein enthoprotin, is involved in the genetic susceptibility to schizophrenia. Am J Hum Genet 2005; 76: 902-907.

90 Sklar P, Pato MT, Kirby A et al: Genome-wide scan in Portuguese Island families identifies $5 \mathrm{q} 31-5 \mathrm{q} 35$ as a susceptibility locus for schizophrenia and psychosis. Mol Psychiatry 2004; 9: $213-218$.

91 Petryshen TL, Middleton FA, Tahl AR et al: Genetic investigation of chromosome 5q GABA(A) receptor subunit genes in schizophrenia. Mol Psychiatry 2005; 10: 1074-1088.

92 Lewis DA, Hashimoto T, Volk DW: Cortical inhibitory neurons and schizophrenia. Nat Rev Neurosci 2005; 6: 312-324.

93 Shifman S, Bronstein M, Sternfeld M et al: A highly significant association between a COMT haplotype and schizophrenia. Am J Hum Genet 2002; 71: 1296-1302.

94 Lohmueller KE, Pearce CL, Pike M, Lander ES, Hirschhorn JN: Meta-analysis of genetic association studies supports a contribution of common variants to susceptibility to common disease. Nat Genet 2003; 33: 177-182.

95 Glatt SJ, Faraone SV, Tsuang MT: Association between a functional catechol-O-methyltransferase gene polymorphism and schizophrenia: meta-analysis of case-control and familybased studies. Am J Psychiatry 2003; 160: 469-476.

96 Fan JB, Zhang CS, Gu NF et al: Catechol-O-methyltransferase gene $\mathrm{Val} / \mathrm{Met}$ functional polymorphism and risk of schizophrenia: a large-scale association study plus meta-analysis. Biol Psychiatry 2005; 57: 139-144.
97 Munafo MR, Bowes L, Clark TG, Flint J: Lack of association of the COMT (Val158/108 Met) gene and schizophrenia: a meta-analysis of case-control studies. Mol Psychiatry 2005; 10: $765-770$.

98 Williams HJ, Glaser B, Williams NM et al: No association between schizophrenia and polymorphisms in COMT in two large samples. Am J Psychiatry 2005; 162: 1736-1738.

99 Tsai SJ, Hong CJ, Hou SJ, Yen FC: Lack of association of catechol$O$-methyltransferase gene Val108/158Met polymorphism with schizophrenia: a family-based association study in a Chinese population. Mol Psychiatry 2006; 11: 2-3

100 Egan MF, Goldberg TE, Kolachana BS et al: Effect of COMT Val108/158 Met genotype on frontal lobe function and risk for schizophrenia. Proc Natl Acad Sci USA 2001; 98: 6917-6922.

101 Ho BC, Wassink TH, O'Leary DS, Sheffield VC, Andreasen NC: Catechol-O-methyl transferase Val158Met gene polymorphism in schizophrenia: working memory, frontal lobe MRI morphology and frontal cerebral blood flow. Mol Psychiatry 2005; 10: 287-298.

102 Badner JA, Gershon ES: Meta-analysis of whole-genome linkage scans of bipolar disorder and schizophrenia. Mol Psychiatry 2002; 7: $405-411$.

103 Lewis CM, Levinson DF, Wise LH et al: Genome scan metaanalysis of schizophrenia and bipolar disorder, part II: schizophrenia. Am J Hum Genet 2003; 73: 34-48.

104 Altshuler D, Brooks LD, Chakravarti A, Collins FS, Daly MJ, Donnelly P, International HapMap Consortium: A haplotype map of the human genome. Nature 2005; 437: 1299-1320. 